\title{
Effects of Pre-Treatments on Pigeon Pea Stalk Fibers
}

\author{
Priyanka Luthra ${ }^{1,2}$, Ram Singh ${ }^{1 *}$ and GS Kapur ${ }^{2}$
}

\begin{abstract}
India being an agricultural country has great potential to utilize fiber derived from agricultural waste. Pigeon pea stalk (PS) is an agricultural waste. The pre-treatments of PS fibers enhance their compatibility with polymer in the area of polymer composites. This work deals with three different types of pre-treatments of PS fiber. The treatments were studied with the help of SEM, XRD, FTIR, TGA and XPS. The PS fibers have undergone laccase enzyme treatment, alkaline treatment with sodium hydroxide and potassium permanganate treatment. The results confirmed the reduction of lignin and hemicellulose after the chemical modification of fibers. The increase in $\%$ crystallinity and thermal stability in treated fibers has been observed. The morphological evaluation showed the increase in surface area and roughness of the fiber surface which is useful for efficient bonding with the polymer matrix.
\end{abstract}

\section{KEYWORDS}

Pigeon pea stalk, Fiber, Composite, Alkaline treatment, Enzymes, Agricultural waste

\section{INTRODUCTION}

Fibers are long thread like material that are used as a source of reinforcement in various kinds of polymer composites (Mohammed et al. 2015). They are either synthetic like carbon, aramid, glass etc or natural like leaf fiber, bast fiber/skin fiber, fruit fiber, stalk fiber, seed fiber etc.

\footnotetext{
${ }^{1}$ Department of Applied Chemistry, Delhi

Technological University, Delhi-110042

${ }^{2}$ Indian Oil Corporation Ltd., Research \& Development Centre, Sector 13, Faridabad-121007, Haryana
}

*Corresponding author; email ramsingh@dtu.ac.in
Synthetic fibers have several advantages like being strong and provide high reinforcement to the composites but also suffer from various disadvantages like posing a threat to the environment for being non-biodegradable and non-renewable. Natural fibers have shown advantages over synthetic fibers mainly with respect to environment and applications towards new polymer composite preparations (Braga et al. 2014).

The natural fiber consists of cellulose, hemicelluloses, lignin and others which include pectin, waxes and extractives. The fibers are used in various studies as a source of reinforcement in polymer composites where the matrix used is either a thermoplastic or thermoset polymeric material. For thermoset, epoxy used as a matrix having good adhesion with natural materials like banana, coconut, bagasse, pineapple leaf etc (Biswas et al. 2011; Maleque et al. 2007; Baranitharan and Mahesh 2014; Acharya et al. 2011; Naidu et al. 2013; Payae and Lopattananon 2009). High-density polyethylene (HDPE), linear low-density polyethylene (LLDPE), polypropylene (PP) and polyester are some of the thermoplastic polymers which have been used as a matrix in preparation of natural fiber filled composites (Roe and Ansell 1985; Kalaprasad et al. 1997; Bahra et al. 2015; Joseph et al. 1999).

The natural fibers have shown disadvantages of high moisture uptake that weakens the interfacial bonding between the polymer matrix and the fiber. This leads to the deterioration in the mechanical properties of composites and dimensional instability. In order to overcome these issues and to improve the fiber matrix adhesion, a pretreatment of the fiber surface have been done for the modification of the surface of the fiber. Some of the common 
chemical treatment practiced includes alkali treatment (Ramadevi et al. 2012; Benyahia and Merrouche 2014; William et al. 2011), potassium permanganate treatment (Khan et al. 2006) and enzyme treatment. Some of the enzymes studied in the reported literature are pectinase (Saleem et al. 2008), cellulose, xylanase (Jayapriya and Vigneswaran 2010), laccase (Islam et al. 2013; Nasir et al. 2013, Cao et al. 2012, Peng et al. 2010).

The utility of agricultural waste as a natural fiber is a step towards sustainable development. India being an agricultural country has great potential to utilize agricultural waste as natural fibers. The pigeon pea (Cajanus cajan) is a perennial legume belongs to the family Fabaceae and is the sixth most important legume crop in the world (Ayenan et al. 2017). India is one of the major pigeon peas producing countries of the world where this plant is more popularly known as Arhar or red gram (Ayenan et al. 2017; Samanta et.al 2013). The stalks are the waste after harvesting the food grain and hence its value addition is vital for sustainability. The pigeon pea stalk has been studied in the preparation of cement bonded composite boards (Aggarwal et al. 2008). We herein report the pretreatment studies of Pigeon pea stalk (PS) fibers using chemical and enzymatic treatments to understand their potential for composite preparations.

\section{RESULTS AND DISCUSSION Morphological study}

The morphological changes in the untreated and treated fiber due to the treatment was studied through SEM (Figure 2). From the SEM images, it is observed that the untreated fibers have been covered with a layer of waxes, oils and extractives which agrees with the literature (Carvalho et al. 2010). The SEM of treated fibers reveals that the fiber become porous and have been partially disintegrated which could be due to extraction of residual lignin that holds the fibrils together. The removal of lignin and presence of depressions leads to increase in the surface area and roughness of the fiber surface which promotes better interaction and formation of mechanical bond more efficiently with the polymer matrix (Pietak et al. 2007).

\section{Crystallinity Index (Cl) study}

The X-ray diffraction patterns of untreated and treated PS fibers have been depicted in figure 3. The diffractogram showed that the treatment has led to the increase in the fiber crystallinity index. The major and intense peaks have been observed at values $2 \theta=16^{\circ}$ and $2 \theta=22^{\circ}$, which represents the cellulose crystallographic planes I101 and 1002 respectively (Yuan et al. 2013). This is same for all the fibers untreated and treated with only variation in intensity. The X-ray apparent crystallinity (\%) of cellulose was calculated using peak height method (Segal et al 1959) by the following equation:

$$
\mathrm{C}=100 \times \frac{I_{200}-I_{\text {non-cryst }}}{I_{200}}|\%|
$$

where: $C$ is the apparent crystallinity [\%], $I_{200}$ gives the maximum intensity of the peak corresponding to the plane in the sample with the Miller indices 200 at a $2 \theta$ angle of between $22-24^{\circ}$.

The non cryst I represent the intensity of diffraction of the non-crystalline material, which is taken at an angle of about $18^{\circ} 2 \theta$ in the valley between the peaks (Terinte et al. 2011). The PSALT fiber peak intensity is the sharpest in comparison to the untreated fiber among all the treatments which confirms that the removal of amorphous portion thus increasing the crystalline portion of the fiber. The diffraction peaks at the $2 \theta$ angles and the \% crystallinity index (calculated as per equation) for all the fibers have been given in table 1 . The increase in $\%$ crystallinity index was observed vis-a-vis comparison of untreated fiber with treated fibers. Alkali treated (PS-ALT) and Potassium permanganate treated (PS-KMT) showed highest increase in crystallinity index than the enzyme treatments. The increase in crystallinity is also reported for the treated fibers in the study by 


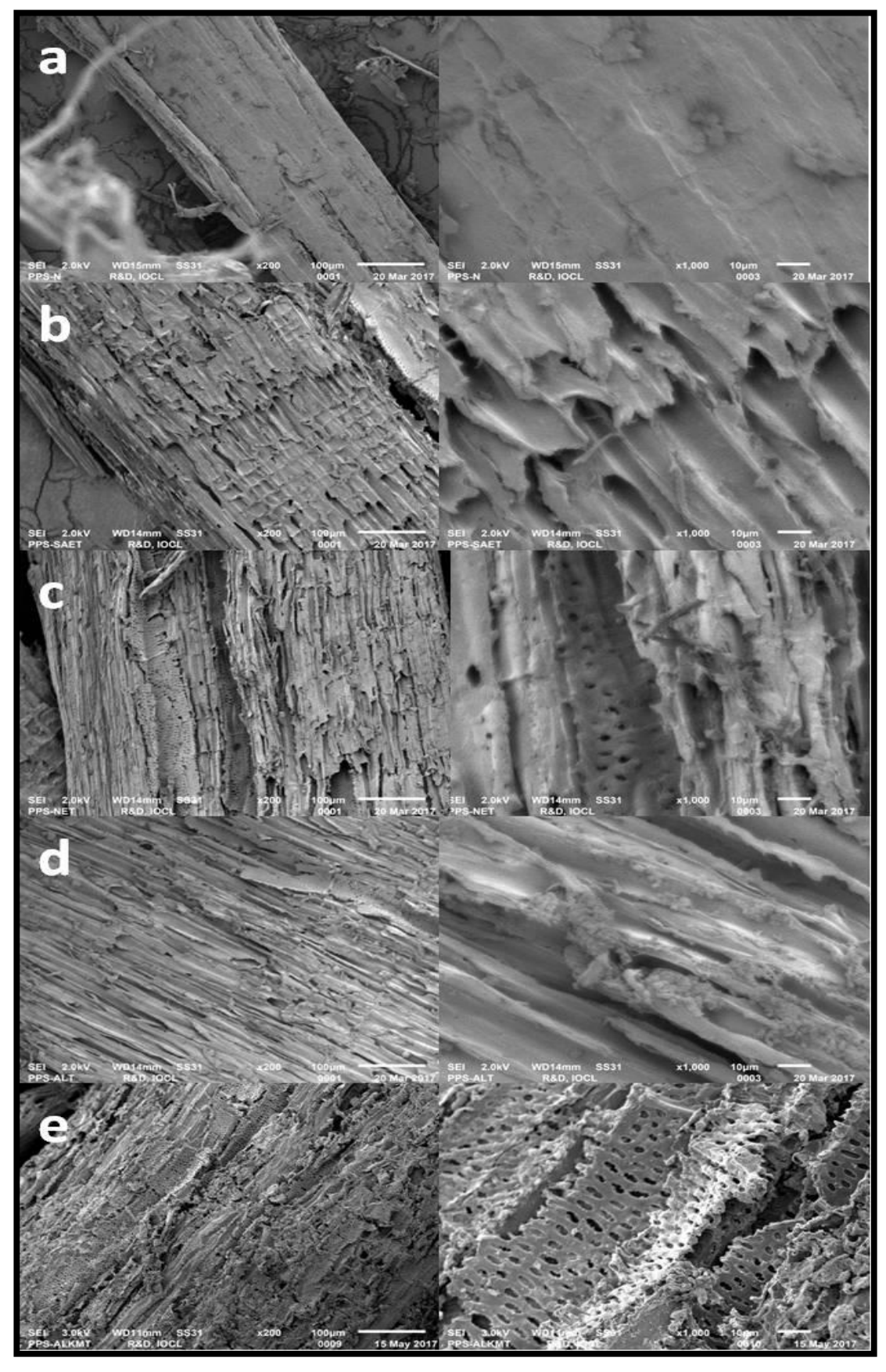

$200 \times \quad 1000$

Figure 2. SEM images of (a) PS-raw and untreated (b) PS-SAET (c) PS-NET (d) PS-ALT (e) PS-KMT fiber at $200 \mathrm{X}$ and $1000 \mathrm{X}$ magnification

Duchemin and Staiger 2009. The increase in \%Cl may be due to the removal of hemicelluloses, which normally separates the cellulose chains (Sinha et al 2007). This resulted in the formation of new hydrogen bonds between some part of the cellulose chains. 


\begin{tabular}{|c|c|c|c|}
\hline Sample Detail & $\mathbf{I}_{\mathbf{0 0 2}}$ & $\mathbf{I}_{\mathbf{1 0 1}}$ & \% Crystallinity Index \\
\hline PS & $1233(16.31)$ & $2720(22.41)$ & 66 \\
\hline PS-SAET & $1025(16.29)$ & $2494(22.44)$ & 73 \\
\hline PS-NET & $977(16.29)$ & $2191(22.28)$ & 79 \\
\hline PS-ALT & $1100(16.25)$ & $2998(22.61)$ & 81 \\
\hline PS-KMT & $834(16.41)$ & $2315(22.71)$ & 68 \\
\hline
\end{tabular}

Table 1. Intensity and Crystallinity index of untreated and treated PS fiber

\section{FTIR study}

Untreated and treated PS fibers were studied by FTIR spectroscopy. Difference in the spectra was observed due to treatments on the fiber (Figure 4). The band at $3100-3600 \mathrm{~cm}^{-1}$ for fibers is due to the $-\mathrm{OH}$ vibration of cellulose structure. The peak observed at $1735 \mathrm{~cm}^{-1}$ for the untreated fibers, associated with the carbonyl group $\mathrm{C}=\mathrm{O}$, proved the presence of pectins, which disappeared after the alkaline extraction with $\mathrm{NaOH}$. The band observed at $1464 \mathrm{~cm}^{-1}$, corresponding to the bending vibration mode of the $\mathrm{CH}_{2}$ group, and at $1530 \mathrm{~cm}^{-1}$, corresponding to the vibration of the $\mathrm{C}-\mathrm{H}$ bond in the aromatic ring which is present in the lignin, have decreased considerably. The peak at $1735 \mathrm{~cm}^{-1}$ which corresponds to carbonyl (Sgriccia et al. 2008) is seen in untreated and enzyme treated (PS-SAET and PS-NET) fibers. However, the intensity has decreased in enzyme treated fibers in comparison to untreated fiber. This peak is not present in PS-ALT and PS-KMT treated fibers which corresponds to $\mathrm{C}=\mathrm{O}$ stretching of acetyl groups of hemicelluloses. The removal of hemicellulose leads to exposure of $\mathrm{OH}$ group of cellulose. The band at $1247 \mathrm{~cm}^{-1}$ is due to $\mathrm{COO}$ stretching in lignin, band intensity has decreased after treatment in comparison to untreated fibers which could be due to degradation or modification of lignin (Islam et al. 2013) that is more pronounced in PS-ALT and PS-KMT treated fibers. is more pronounced in PS-ALT and PSKMT treated fibers.

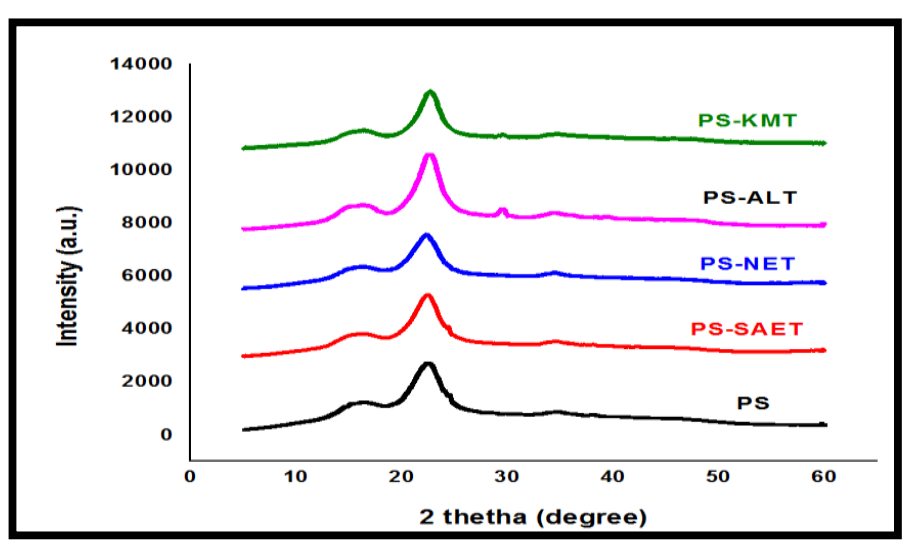

Figure 3. XRD spectrum of untreated and treated PS fiber

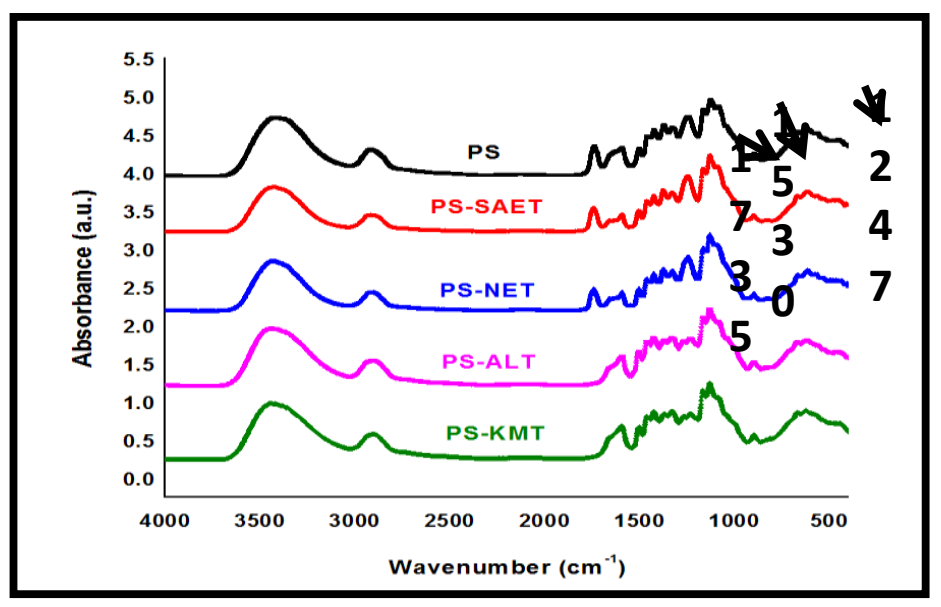

Figure 4. FTIR spectra of untreated and treated PS fibers 


\section{Thermal study}

Two-step degradation is observed in PS untreated and the enzyme treated fiber whereas in the case of alkali and potassium permanganate treated fibers, single step degradation is observed (Figure 5a). In the first step, a weight loss is observed due to desorption of water. Though the fibers have been analyzed after drying but due to hydrophilic nature of the natural fibers, total elimination of water may not be possible (Guimarães et al 2009). The mass loss of natural fiber is due to the cellulose, hemicelluloses and lignin degradation. Hemicellulose decomposes mainly between 220$315 \circ \mathrm{C}$, cellulose decomposes between 315$400^{\circ} \mathrm{C}$ and degradation of lignin after that (Yang et al. 2007). $T_{\max }$ is the temperature at which rate of mass loss is maximum (obtained from DTG trace). The $T_{\max }, \%$ weight loss and $\%$ residue left is given in table 2 . The weight loss below $250^{\circ} \mathrm{C}$ is negligible. Maximum weight loss occurs in the temperature zone of $250-400 \circ C$. The initial weight loss peak which is due to the loss of moisture is in the temperature region $~ 70-85$ o $C$ for untreated and treated fiber. The $\%$ weight loss (due to moisture) of treated fiber is more than the untreated one which could be due to more pores in the treated ones. This result is in agreement with the reported study (Khan et al. 2012). Above the main degradation peak i.e. $T_{\max }$ all the volatile material is taken off from the sample which further results in the final leftover called the residual char.

In DTG scans (Figure $5 \mathrm{~b}$ ) which is studied as a function of rate of weight loss $(\mathrm{mg} / \mathrm{min})$ versus temperature, in case of untreated fibers two peaks are observed i.e at $\sim 294$ ㅇ $\mathrm{C}$ and the other at $348^{\circ} \mathrm{C}$. The first peak is for the degradation of hemicellulose and the second is of cellulose and lignin approximately. The $12-15 \circ \mathrm{C}$ and $5-6 \circ \mathrm{C}$ increase in degradation peak temperature of enzyme treated and alkali and potassium permanganate treated fiber respectively have been observed. This indicates better thermal stability of treated fibers in comparison to untreated one. It is also reported that the alkali treatment reduces the hemicelluloses in the fiber, which makes it the fiber more stable (Saha

\begin{tabular}{|c|c|c|c|c|}
\hline $\begin{array}{c}\text { Sample } \\
\text { Detail }\end{array}$ & $\begin{array}{c}\text { Temperature } \\
\text { range (C) }\end{array}$ & $\begin{array}{c}\% \\
\text { Weight } \\
\text { loss }\end{array}$ & $\begin{array}{l}\text { Residue } \\
\text { char (\%) }\end{array}$ & $T_{\max }(\stackrel{\circ}{ } \mathbf{C})$ \\
\hline PS & $\begin{array}{c}\text { RT-150 } \\
150-250 \\
250-400 \\
400-800\end{array}$ & $\begin{array}{c}5.21 \\
3.75 \\
66.28 \\
5.77\end{array}$ & 19.07 & 348.6 \\
\hline PS-SAET & $\begin{array}{c}\text { RT-150 } \\
150-250 \\
250-400 \\
400-800\end{array}$ & $\begin{array}{c}6.01 \\
1.47 \\
71.54 \\
5.42\end{array}$ & 15.82 & 363.7 \\
\hline PS-NET & $\begin{array}{l}\text { RT-150 } \\
150-250 \\
250-400 \\
400-800\end{array}$ & $\begin{array}{c}6.91 \\
1.53 \\
74.66 \\
8.75\end{array}$ & 16.59 & 360.8 \\
\hline PS-ALT & $\begin{array}{c}\text { RT-150 } \\
150-250 \\
250-400 \\
400-800\end{array}$ & $\begin{array}{c}7.22 \\
1.19 \\
66.65 \\
6.9\end{array}$ & 18.01 & 354.4 \\
\hline PS-KMT & $\begin{array}{c}\text { RT-150 } \\
150-250 \\
250-400 \\
400-800\end{array}$ & $\begin{array}{c}7.01 \\
2.42 \\
56.7 \\
10.43\end{array}$ & 23.49 & 353.6 \\
\hline
\end{tabular}

et al. 1991, Khan et al. 2012).

Table 2. Results of Thermogravimetric Analysis (TGA) for untreated and treated fiber

\section{X-ray Photon Spectroscopic study}

XPS spectra (Figures $6 a$ and $6 \mathrm{~b}$ ) were obtained for untreated and treated PS fibers. Cellulose and lignin have an $\mathrm{O} / \mathrm{C}$ ratio of 0.83 and 0.35 
respectively (Zhong et al. 2010). Increase in O/C ratio indicates lower lignin concentration (Dorris et al. 1978a and 1978b). The changes in carbon $(C)$ and oxygen $(O)$ regions have been shown in figures $6 a$ and $6 b$ respectively. Elemental composition in the untreated and different treated fibers obtained from survey spectra have been given in table 3 . The spectra of all the fibers contained carbon and oxygen primarily which form the structure of these fibers while calcium, phosphorous, magnesium, aluminium and potassium were detected but present in small quantities.

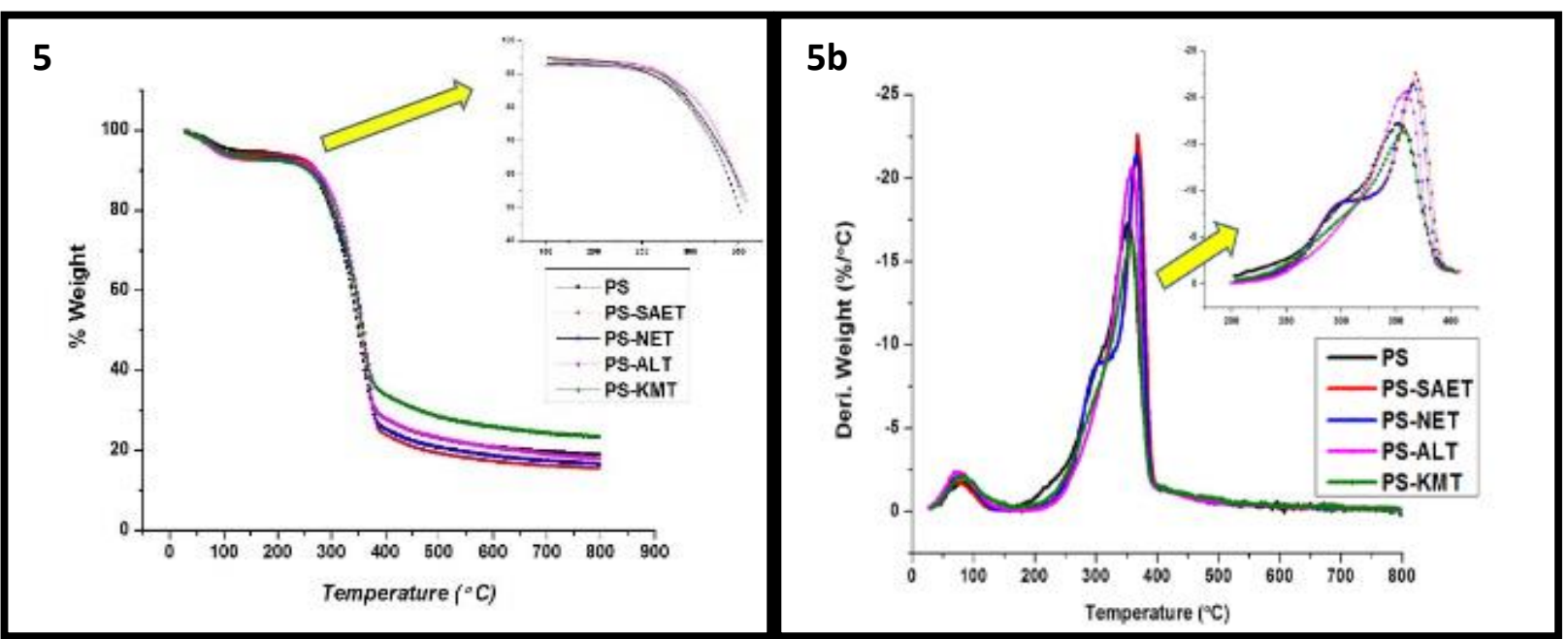

Figure $\mathbf{5 a} \boldsymbol{\mathbf { a }} \mathbf{b}$ : TG and DTG traces of PS untreated and treated fiber respectively in nitrogen atmosphere (heating rate $10^{\circ} \mathrm{C} / \mathrm{min}$ )

As observed through the evaluation and the results tabulated, it is observed that the treated and untreated fibers have less $\mathrm{O} / \mathrm{C}$ than 0.83 which confirms that the surface has a greater proportion of lignin and waxes on it (Sgriccia et al 2008). It has been found that the $\mathrm{O} / \mathrm{C}$ ratio increase on the treatment of fibers vis-a-vis comparison of untreated fiber. This took place due to increase of the oxygen exposure on fiber surface after the removal of soluble extractives. A decrease in $\mathrm{N} / \mathrm{C}$ ratio after treatment of fiber also suggested that the surface was affected by the treatment procedure.

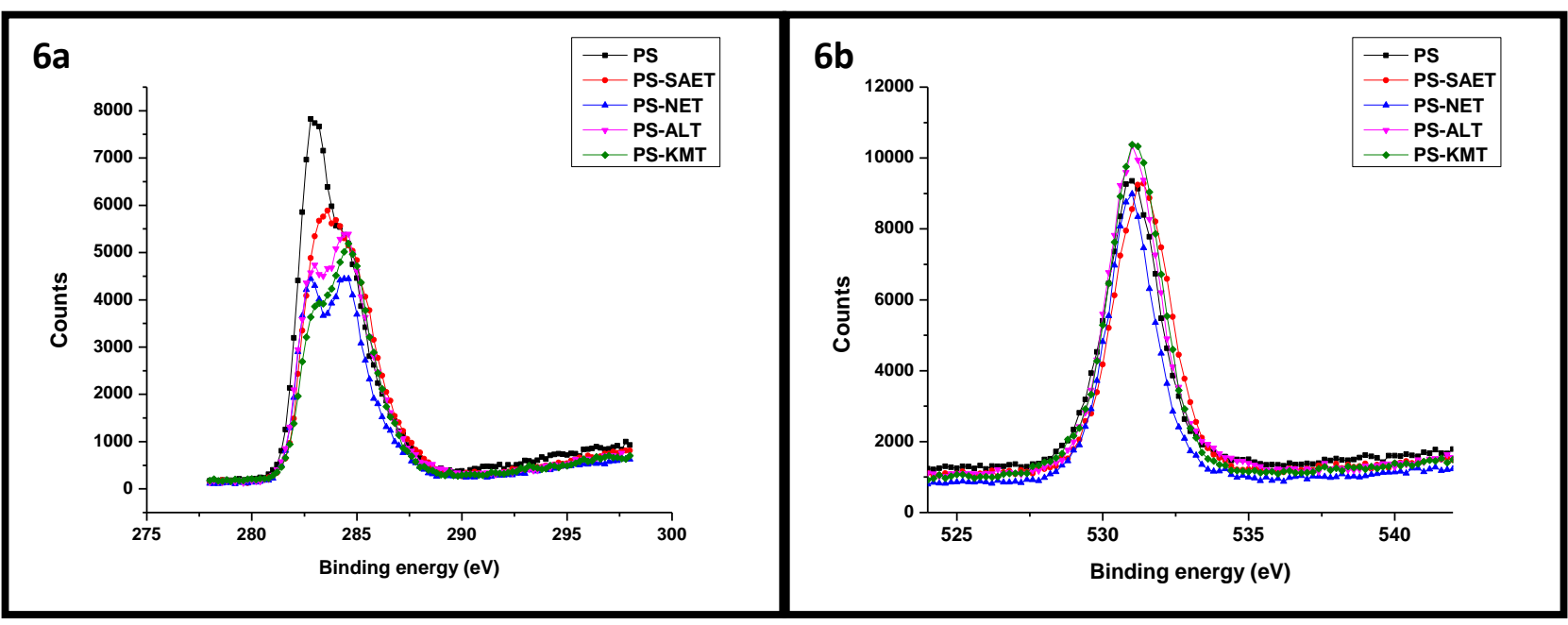

Figure $6 \mathbf{a} \boldsymbol{\&}$ b: Carbon and Oxygen region respectively of XPS spectra in untreated and treated PS fibers 


\begin{tabular}{|c|c|c|c|c|c|}
\hline & PS & PS-SAET & PS-NET & PS-ALT & PS-KMT \\
\hline C & 70.6 & 70.0 & 68.1 & 67.4 & 64.1 \\
\hline $\mathbf{N}$ & 27.1 & 28.1 & 30.8 & 31.4 & 34.2 \\
\hline 0 & 1.5 & 1.6 & 0.8 & 0.6 & 0.7 \\
\hline $\mathrm{Ca}$ & 0.3 & 0.3 & 0.3 & 0.6 & 0.7 \\
\hline $\mathbf{P}$ & 0.2 & 0.1 & - & 0.1 & - \\
\hline $\mathrm{Mg}$ & 0.2 & - & - & - & 0.3 \\
\hline Al & 0.2 & - & - & - & - \\
\hline $\mathbf{K}$ & 0.1 & - & - & - & - \\
\hline C-C & 18 & 18 & 20 & 14 & 11 \\
\hline C-O & 42 & 42 & 22 & 27 & 28 \\
\hline$C=0$ & 30 & 31 & 45 & 42 & 49 \\
\hline Carbonate & 2 & 1 & 2 & 3 & 1 \\
\hline $0 / C$ & 0.38 & 0.40 & 0.43 & 0.44 & 0.48 \\
\hline$N / C$ & 0.021 & 0.022 & 0.011 & 0.008 & 0.009 \\
\hline
\end{tabular}

Table 3: Elemental Composition of Untreated and Treated PS fiber obtained from Survey Spectra

\section{Bulk Density}

Bulk density is an intrinsic property. This is the ratio of the mass of the material and the volume they occupy. The particle volume, internal pore volume and inter void volume constitutes the total volume.

\begin{tabular}{|c|c|}
\hline Sample Detail & $\begin{array}{c}\text { Bulk Density } \\
\left(\mathrm{g} / \mathrm{cm}^{3}\right)\end{array}$ \\
\hline PS & $199 \pm 5.0$ \\
\hline PS-SAET & $152 \pm 1.8$ \\
\hline PS-NET & $134 \pm 0.7$ \\
\hline PS-ALT & $156 \pm 2.8$ \\
\hline PS-KMT & $172 \pm 1.4$ \\
\hline
\end{tabular}

Table 4. Bulk density of untreated and treated fiber
Bulk density of untreated fiber is more than the treated fiber (Table 4). Bulk density of PS-NET fiber is the lowest of all the treatments given to the fiber.

\section{CONCLUSIONS}

Chemical surface modification or treatment of natural fibers helps in increasing the adhesion between the fibers which are hydrophilic in nature and the matrix being hydrophobic in nature. Modification of surface of fiber has been explored using different treatments like enzymes, alkali and potassium permanganate. SEM observation confirmed that the all the treatments were capable in removing waxes and the unwanted impurities and thus making the surface of the fiber porous. FTIR spectra showed the removal of hemicelluloses and lignin in all the treatments provided to the PS fiber. An 
increase in crystallinity index was observed by XRD in comparison to the untreated fiber. The crystallanity index was maximum for potassium permanganate treatment. The crystallanity index increased $\sim 2-23 \%$ for treated PS fibers in comparison to untreated fiber. Thermal studies carried out using TGA also confirmed an increase in the thermal stability of fiber which is confirmed by the increase in $T_{\max }$ which has been increased by $\sim 5-15^{\circ} \mathrm{C}$ for different kind of treatment done on the fiber. XPS studies confirmed the increase in $\mathrm{O} / \mathrm{C}$ ratio which shows decrease in lignin content and the soluble extractives thus increasing the oxygen exposure on fiber surface.

From the study conducted, it was observed that the chemical treatment takes an edge over the enzyme treatment of fibers in terms of increase in thermal stability, \% crystallinity and removal of lignin. The enzyme treatment is equally suitable considering the environmental benefits. The study showed that the agricultural waste, PS has potential to be utilized as a source of reinforcement. The pre-treated PS fiber may further be used to prepare polymer (PE/PP) composites.

\section{EXPERIMENTAL}

\section{Materials}

Pigeon pea stalk (PS) was collected from Agra, India. The stalk was cut manually into $10-15 \mathrm{~cm}$ small pieces and grinded in a Retsch cutting mill, SM 200 with maximum particle size up to $2 \mathrm{~mm}$ (Figure 1). Chemicals used for the treatment of PS fiber like sodium hydroxide (analytical grade with $97 \%$ purity), potassium permanganate (analytical grade with $\geq 98.5 \%$ purity) and acetic acid (analytical grade with $\geq 98.8 \%$ purity) are purchased from reputed company and used without further purification. Laccase enzyme obtained from two sources i.e. L2157 (Rhus Vernicifera) from Sigma and Novozyme-51003 (Aspergillus oryzea) from Novozyme, Denmark. The ash content of PS fiber powder was measured using quartz crucible. The crucible containing known weight of PS fiber was heated at $800^{\circ} \mathrm{C}$ in microwave furnace for four hours. The ash content was calculated to be $1.5 \%$ approximately using weight difference method. The chemical composition of Pigeon Pea stalk from Indian origin consists of Cellulose (46\%), holocellulose (77\%), acid insoluble lignin (22\%), cellulose to lignin ratio $(2: 1)$, pentosan $(18 \%)$ (Elzaki et al. 2012).

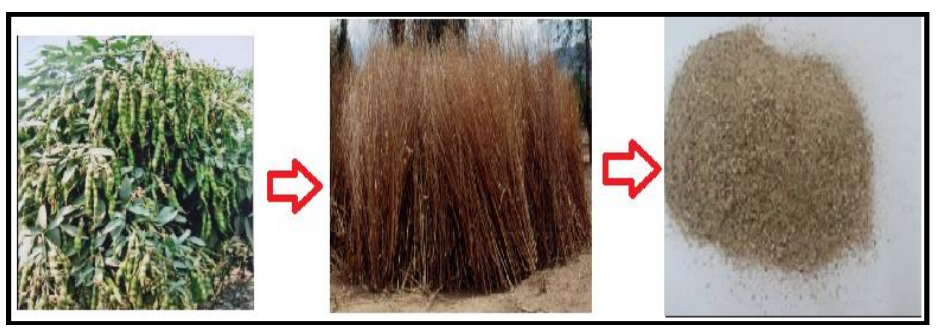

Figure 1. Pigeon Pea Stalk used in grinded (fibers) form

\section{Methods of treatment}

The fiber has been studied for three types of pretreatments i.e. alkaline, potassium permanganate and laccase enzyme treatment.

\section{Alkaline treatment of fiber:}

PS fibers were soaked in $5 \%(\mathrm{w} / \mathrm{v})$ sodium hydroxide solution at $23^{\circ} \mathrm{C}$ maintaining a solution: fiber ratio of $20: 1(\mathrm{ml} / \mathrm{g})$ for $24 \mathrm{~h}$ under continuous stirring. The sodium hydroxide solution was prepared in distilled water. After treatment, fibers were thoroughly washed with distilled water to remove any traces of alkali on the fiber surface and to further attain $7.0 \mathrm{pH}$. The treated fibers (PS-ALT) were then dried.

Potassium permanganate treatment of fiber:

Alkali treated PS fibers were soaked in $0.5 \%$ concentrated $\mathrm{KMnO}_{4}$ /acetone for 10 minutes with continuous stirring (Khan et al. 2015), maintaining a solution to fiber ratio of $15: 1$ $(\mathrm{ml} / \mathrm{g})$. After treatment fibers were thoroughly washed with distilled water. The treated fibers (PS-KMT) were then dried.

\section{Lacasse treatment of fiber:}

Novozyme 51003: Enzyme treatment of PS fiber was carried out at $\mathrm{pH} 5.5$ with enzyme dosage of $1.5 \mathrm{wt} \%$ for $4 \mathrm{~h}$ under continuous stirring at $23^{\circ} \mathrm{C}$ (Islam et al. 2013). The $\mathrm{pH}$ of the solution was 
maintained to 5.5 using acetic acid. A solution to fiber ratio of $30: 1(\mathrm{ml} / \mathrm{g})$ was taken for the experiment. Air flow was maintained for the better treatment of fibers in the vessel containing solution of fiber and enzymatic solution throughout the treatment time. Then the fibers were washed with distilled water until a $\mathrm{pH}$ of 7.0 was reached for avoiding any acidic effect on them. The treated fibers (PS-NET) were then dried.

Sigma L2157: Enzyme treatment of $30 \mathrm{u} / \mathrm{g}$ was used to treat a PS fiber for $2 \mathrm{~h}$ under continuous stirring at $23^{\circ} \mathrm{C}$ at $\mathrm{pH} 5.5$ maintained with acetic acid (Cao et al. 2012). A solution to fiber ratio of $30: 1$ ( $\mathrm{ml} / \mathrm{g}$ ) was maintained for the experiment. Air flow was taken for the better treatment of fibers in the vessel containing solution of fiber and enzymatic solution throughout the treatment time. Then the fibers were washed with distilled water until a $\mathrm{pH}$ of 7.0 was reached for avoiding any acidic effect on them. The treated fibers (PS-SAET) were then dried.

\section{Characterization}

Scanning Electron Microscopy (SEM): Morphology of PS fibers was performed using EVO-50 scanning electron microscope (SEM) at the conditions of accelerating voltage of $2.0 \mathrm{kV}$. Before being examined, the fibers being nonconducting were coated with a thin layer of gold prior to conduction and the final morphologies of the samples were studied (Kaushik et al. 2012).

Fourier Transform Infrared Spectroscopy (FTIR): The FTIR spectra at room temperature were measured in the spectral range of 4000 to 400 $\mathrm{cm}^{-1}$ using an FTIR spectrometer (Shimadzu IR Prestige 21). A total of 100 scans were taken for each sample with a resolution of $4 \mathrm{~cm}^{-1}$. The dried PS fibers were pulverized by ball milling before performing spectroscopic measurements, which were obtained of dried PS fibers.

Crystallinity Index: PS fibers were placed in a WAXD analysis using a Rigaku Rint 2000 PC,
Rotating anode-18 KW X-ray diffractometer at room temperature. The XRD patterns of untreated and treated fibers were obtained in the $2 \theta$ range of $5-60$ at a scan rate of $0.3 \% / \mathrm{min}$. Thermogravimetric analysis (TGA): In order to study the change in thermal stability after treatment of PS fibers, TGA was performed using a TA Instrument TGA Q 500. Sample weighing 8$10 \mathrm{mg}$ were taken for the analysis. Thermogravimetric (TG)/derivative thermogravimetric (DTG) traces were recorded at a heating rate of $10^{\circ} \mathrm{C} / \mathrm{min}$ in $\mathrm{N}_{2}$ atmosphere in the temperature ranging from room temperature to $800^{\circ} \mathrm{C}$.

X-ray photoelectron Spectroscopy (XPS): XPS analysis was performed with a PHI Versa Probe III using a micro-focusing monochromatic Al K $\alpha$ $X$-ray source at an operating pressure of not more than $10^{-8}$ mbar. The spectrophotometer was equipped with a monochromator $\mathrm{Al} \mathrm{K \alpha} \mathrm{X-}$ ray source $(\mathrm{hv}=1486.6 \mathrm{eV}$ ) of $200 \mathrm{~W}$ operating at $15 \mathrm{kV}$. The kinetic energy of the photoelectrons was determined with a hemispherical analyze set to pass energy of $187.0 \mathrm{eV}$ for the survey spectra and of $20.0 \mathrm{eV}$ for high resolution spectra respectively. During all measurements, electrostatic charging of the sample was over compensated by means of a low energy electron source working in combination with a magnetic immersion lens. Later, all recorded peaks were corrected for electrostatic charging by setting the component peak of the saturated hydrocarbons in the $\mathrm{C} 1 \mathrm{~s}$ spectrum to $284.8 \mathrm{eV}$. In all experiments the base pressure in the analysis chamber was less than $10^{-8} \mathrm{~m}$ bar.

Bulk Density: Bulk density of PS fibers was obtained by adding a known mass of powder to a graduated cylinder. The density is calculated as mass/volume.

\section{ACKNOWLEDGEMENT}

The authors would like to acknowledge Analytical Department of IOCL, Faridabad for their support and service provided. 


\section{REFERENCES}

Acharya, S.K., Mishra, P. and Sapuan, S.M. 2011, 'Effect of surface treatment on the mechanical properties of baggase fiber reinforced polymer composite', BioRes., Vol. 6 no. 3, pp. 3155-3165. Aggarwal, L.K., Agarwal, S.P., Thapliyal, P.C. and Karade, S.R. 2008, 'Cement-bonded composite boards with arhar stalks', Cement Concrete Comp., vol. 30, no. 1, pp. 44-51.

Ayenan, M.A.T., Danquah, A., Ahoton, L.E. and Ofori, K. 2017, 'Utilization and farmers' knowledge on pigeonpea diversity in Benin, West Africa', J. Ethnobiol. Ethnomed., Vol. 13, pp. 37.

Bahra, M.S., Aggarwal, L. and Gupta, V.K. 2015, 'Natural Fiber Reinforced Polypropylene Composites: A Review', IOSR J. Mech. Civil Engineer., pp. 43-45.

Baranitharan, P. and Mahesh, G. 2014, 'Alkali Treated Maize Fibers Reinforced with Epoxy Poly Matrix Composites', Int. J. Innovat. Sci. Modern Engineer., Vol. 2, no. 5, pp. 1-7.

Benyahia, A. and Merrouche, A. 2014, 'Effect of chemical surface modifications on the properties of Alfa fiber-polyster composites', Polym-Plastics Tech. Engg., Vol. 53, pp. 403-410.

Biswas, S., Kindo, S. and Patnaik, A. 2011, 'Effect of fiber length on Mechanical Behavior of Coir Reinforced Epoxy Composites', Fibers Poly., Vol. 12, no. 1, pp. 73-78.

Braga, R.A., Magalhaes Jr, P.A.A. and Sathishkumar 2014, 'Rear bumper laminated in jute fiber with polyester resin', IJERA, vol. 4, 9 Version 1, pp. 174-184.

Cao, Y., Chan, F., Chui, Y.H. and Xiao, H. 2012, 'Characterization of Flax Fibers Modified by Alkaline, Enzyme, and Steam Heat treatments', BioRes. Vol. 7, no. 3, pp. 4109-4121.

Carvalho, K.C.C., Mulinari, D.R., Voorwald, H.J.C. and Cioffi M.O.H. 2010, 'Chemical Modification effect on the Mechanical Properties of HIPS/Coconut fiber Composites', BioRes., Vol. 5, no. 2, pp. 1143-1155.

Dorris, G.M. and Gray, D.G. 1978a, 'The surface analysis of paper and wood fibers by ESCA. I Application of cellulose and lignin', Cellulose Chem. Tech., Vol. 12, pp. 9-23.
Dorris, G.M., and Gray, D.G. 1978b, 'The surface analysis of paper and wood fibers by ESCA. II. Surface composition of mechanical pulps', Cellulose Chem. Tech., Vol. 12, pp. 721-734.

Duchemin, B. and Staiger, M.P. 2009, 'Treatment of Harakeke Fiber for Bicomposite', J. Appl. Polym. Sci., Vol.112, pp. 2710-2715.

Elzaki, O.T., Khider, T.O. and Omer, S.H. 2012, 'Pulp and Papermaking Characteristics of Cajanus cajan Stems from Sudan', Amer.-Eur. J. Agric. Env. Sci. Vol. 12, no. 2, pp. 159-163.

Guimarães, J.L., Frollini, E., da Silva, C.G., Wypych, F. and Satyanarayana, K.G. 2009, 'Characterization of banana, sugarcane bagasse and sponge gourd fibers of Brazil', Ind. Crops Prod., Vol. 30, pp. 407-415.

Islam, M.R., Beg, M.D.H. and Gupta, A. 2013, 'Characterization of Laccase-Treated Kenaf Fiber Reinforced Recycled Polypropylene Composites', BioRes., Vol. 8, no. 3, pp. 3753-3770.

Jayapriya, J. and Vigneswaran, C. 2010, 'Process optimization for biosoftening of lignocellulosic fiber with white rot fungi and specific enzyme systems', J. Nat. Fiber, Vol. 7, no. 1, pp.17-33.

Joseph, P.V., Kuruvilla, J. and Thomas, S. 1999, 'Effect of processing variables on the mechanical properties of sisal-fiber reinforced composites', Comp. Sci. Tech., Vol. 59, no. 11, pp. 1625-1640. Kalaprasad, G., Joseph, K. and Thomas, S. 1997, 'Theoretical modeling of tensile properties of short sisal fiber reinforced low-density polyethylene composites', J. Mat. Sci., Vol. 32, pp. 4261-4267.

Kaushik, V.K., Kumar, A. and Kalia, S. 2012, 'Effect of Mercization and Benzoyl Peroxide Treatment on Morphology, thermal Stability and Crystallinity of Sisal Fibers', Int. J. Textile Sci., Vol. 1, no. 6, pp. 101-105.

Khan, G.M.A., and Alam, Md. S. 2012, 'Thermal Characterization of chemically treated coconut husk fiber', Ind. J. Fiber Textile Res., Vol. 37, pp. 20-26.

Khan, G.M.A., Shaikh, H., Alam, M.S., Gafur, M.A. and Zahrani, S.M. 2015, 'Effect of Chemical Treatments on the Physical properties of Nonwoven Jute/PLA Bicomposites', BioRes., Vol. 10, no. 4, pp. 7386-7404. 
Khan, M.A., Hassan, M.M., Taslima, R. and Mustafa, A.I. 2006, 'Role of pretreatment with potassium permanganate and urea on mechanical and degradable properties of photocured coir (Cocos nucifera) fiber with 1,6hexanediol diacrylate', J. Appl. Polym. Sci., Vol. 100, pp. 4361-4368.

Maleque, M.A., Belal, F.Y. and Sapuan, S.M. 2007, 'Mechanical properties study of pseudostem banana fiber reinforced epoxy composite', Arab. J. Sc. Eng, Vol. 32, no. 2B, pp. 359-364.

Mohammed, L., Ansari, M.N.M., Pua, G., Jawaid, M. and Islam, M.S. 2015, 'A review on natural fiber reinforced polymer composite and its applications', Int. J. Polym. Sci., Vol. 2015, Article ID 243947.

Naidu, A.L., Raghuveer, D., and Suman, P. 2013, 'Studies on characterization and mechanical behavior of banana peel reinforced epoxy composites', Int. J. Sci. Eng. Res., Vol. 4, no. 6, pp. 844.

Nasir, M., Gupta, A., Beg, M.D.H., Chua, G.K., Jawaid, M., Kumar, A. and Khan, T.A. 2013, 'Fabricating eco-friendly binderless fiberboard from lacasse-treated rubber wood fiber', BioRes., Vol. 8, no. 3, pp. 3599-3608.

Payae, Y. and Lopattananon, A. 2009, 'Adhesion of pineapple leaf fiber to epoxy matrix: The role of surface treatments', Songklanakarin J. Sci. Technol., Vol. 31, no. 2, pp. 189-194.

Peng, X., Zhong, L., and Sun, R. 2010, 'Lacaase and alkali treatments of cellulose fiber: Surface lignin and its influences on fiber surface properties and interfacial behavior of sisal fiber/phenolic resin composites', Comp. Part A: Appl. Sci. Manufact., Vol. 41, no. 12, pp. 18481856.

Pietak, A., Korte, S., Tan, E., Downard, A. and Staiger, M.P. 2007, 'Atomic force microscopy characterization of the surface wettability of natural fibers', Appl. Surface Sci., Vol. 253, no.7, pp. 3627-3635.

Ramadevi, P., Sampathkumar D., Srinivasa C.V. and Bennehalli B. 2012, 'Effect of alkali treatment on water absorption of single cellulosic abaca fiber', Biores., Vol. 7, no. 3, pp. 3515-3524.
Roe, P.J. and Ansell, M.P. 1985, 'Jute-reinforced polyester composites', J. Mater. Sci., Vol. 20, no. 11, pp. 4015-4020.

Saha, S.C., Ray P.K., Pandey S.N. and Goswami, K. 1991, 'IR and X-ray diffraction studies of raw and chemically treated pineapple fiber', J. Appl. Polym. Sci., Vol. 42, no. 10, pp. 2767-2772.

Saleem, Z., Rennebaum, H. and Pudel, F. 2008, 'Treating bast fibers with pectinase improves mechanical characteristics of reinforced thermoplastic composites', Comp. Sci. Tech., Vol. 68, no. 2, pp. 471-476.

Samanta, A.K., Jayapal, N., Kolte A.P., Senani, S., Sridhar, M., Mishra, S., Prasad, C.S., Suresh, K.P. 2013, 'Application of Pigeon Pea (Cajanus Cajan) stalks as raw material for xylooligosaccharides production', Appl. Biochem. Biotech., Vol. 169, pp. 2392-2404.

Segal, L., Creely, J.J., Martin, A.E.Jr. and Conrad, C.M. 1959, 'An empirical method for estimating the degree of crystallinity of native cellulose using X-ray Diffractometer', Tex. Res. J., Vol. 29, pp. 786-794.

Sgriccia, N., Hawley, M.C., Misra, M. 2008, 'Characterization of natural fiber surfaces and natural fiber composites', Comp.: Part A, Vol. 39, pp. 1632-1637.

Sinha, E. and Rout, S.K. 2007, 'Influence of fibre - surface treatment on structural, thermal and mechanical properties of jute fiber and its composite', Bull. Mater. Sci., Vol. 32, no. 1, pp. 65-76.

Terinte, N., Ibbett, R. and Schuster, K.C. 2011, 'Overview on native cellulose and microcrystalline cellulose I structure studied by $X$ ray diffraction (WAXD): Comparison between measurement techniques', Len. Ber., Vol.89, pp. 118-131.

William, T., Hosur, M., Theodore, M., Netravali, A., Rangari, V. and Jeelani, S. 2011, 'Time effects on morphology and bonding ability in mercerized natural fibers for composite reinforcement', Int. J. Polym. Sci., Vol. 2011, Article ID 192865.

Yang, H., Yan, R., Chen, H., Lee, D.H. and Zheng, C. 2007, 'Characteristics of hemicelluloses, cellulose and lignin pyrolysis', Fuel, Vol. 86, pp. 1781-1788. 
Yuan, L., Wan, J., Ma, Y., Wang, Y., Huang, M., and Chen, Y. 2013, 'the content of different hydrogen bond models and crystal structure of eucalyptus fibers during beating', Biores., Vol. 8, no. 1, pp. 717-734.

Zhong, L., Fu, Shiyu., Li, Feng. and Zhan, H. 2010, 'Chlorine dioxide treatment of sisal fiber: Surface lignin and its influences in fiber surface characteristics and interfacial behavior of sisal fiber/phenolic resin composites', Biores., Vol. 5, no. 4, pp. 2431-2446. 